\title{
Breakfast consumption determinants among female high school students of Yazd Province based on Pender's Health Promotion Model
}

\author{
Akram Mehrabbeik ${ }^{1}$, Seyed Saeed Mazloomy Mahmoodabad ${ }^{2}$, Hassan Mozaffari Khosravi ${ }^{3}$, Hossein \\ Fallahzadeh $^{4}$
}

\begin{abstract}
${ }^{1}$ M.Sc. in Health Education, Department of Health Education \& Promotion, Faculty of Health, Shahid Sadoughi University of Medical Sciences, Yazd, Iran

${ }^{2}$ Ph.D. in Health Education, Professor, Department of Health Education \& Promotion, Faculty of Health, Shahid Sadoughi University of Medical Sciences, Yazd, Iran

${ }^{3}$ Ph.D. in Nutritional Sciences, Professor, Department of Nutrition, Faculty of Health, Shahid Sadoughi University of Medical Sciences, Yazd, Iran

${ }^{4}$ Ph.D. in Biostatistics, Professor, Department of Biostatistics, Faculty of Health, Shahid Sadoughi University of Medical Sciences, Yazd, Iran
\end{abstract}

Type of article: Original

\begin{abstract}
Background and Aim: Despite the importance of breakfast, especially for students, unfortunately, this meal is usually ignored in daily routine. The aim of this study was to identify determinants among female high school students of Yazd province based on the Pender Health Promotion Model.

Methods: This was a cross-sectional study conducted to examine 200 female high school students of Yazd, selected by cluster sampling method in 2016. A researcher-made questionnaire, based on Pender's Health Promotion Model, was used as a data collection tool. A panel of experts and Cronbach's alpha coefficient were used to confirm the questionnaire validity and reliability. In order to analyze descriptive data, SPSS version 22 was used. AMOS software (v.23) was employed for path analysis.

Results: Direct impact of activity -related affect (0.300), interpersonal influences $(0.276)$, and perceived barriers to eating breakfast $(-0.223)$ were approved at significance level $p<0.000$. By influencing perceived barriers, perceived self-efficacy and previous related behavior indirectly affected breakfast consumption. These components determined $33 \%$ of breakfast consumption.

Conclusion: By planning to create a positive feeling in students to have breakfast, to involve family and friends to encourage students to eat breakfast, to reduce barriers to have breakfast by increasing students' self-efficacy, the behavior of having breakfast among students can be improved.

Keywords: Breakfast, Students, Health Promotion Model
\end{abstract}

\section{Introduction}

Childhood and adolescence is a growth stage, during which, the human body needs more nutrients (1), yet it is the most critical period for the correction of a dietary pattern (2). One of these patterns is breakfast consumption which has positive effects on nutrition and cognitive functions (3). The importance of breakfast consumption is so that it can be used as a marker to identify children at risk for an unhealthy lifestyle (4). Unfortunately, this meal is usually eliminated from the daily diet. In 2010, a research on a group of high school students of several countries showed that $63.1 \%$ of them do not have breakfast; a habit which is more common among girls rather than boys (5). Studies conducted in Iran showed that 30.8\% of overweight female students in Shahin Shahr (6), 21\% of students in Qom (7), $10.4 \%$ of students in Torbat-e Heydarieh (8) and 5.3\% of students in Ramsar do not have breakfast (9). Not

\section{Corresponding author:}

Professor Dr. Seyed Saeed Mazloomy Mahmoodabad, Department of Health Education \& Promotion, Faculty of Health, Shahid Sadoughi University of Medical Sciences, Yazd, Iran.

Tel: +98.3531492186, Email: mazloomy.stu@gmail.com

Received: March 01, 2017, Accepted: May 30, 2017, Published: August 2017

iThenticate screening: April 17, 2017, English editing: June 18, 2017, Quality control: July 12, 2017

(C) 2017 The Authors. This is an open access article under the terms of the Creative Commons Attribution-NonCommercialNoDerivs License, which permits use and distribution in any medium, provided the original work is properly cited, the use is non-commercial and no modifications or adaptations are made. 
having breakfast increases appetite for the next meal which is associated both with increased weight gain and hormonal and metabolic responses to consumed food after breakfast. It can also be a predisposing risk for cardiovascular disease and diabetes $(10,11)$. Breakfast removal is associated with the probability of increased fast food and soda consumption and unhealthy eating behavior, in general (5). On the other hand, individuals who consume breakfast every day have lower body fat content than those who do not have breakfast (12), are two times less likely to be overweight or obese (13), and gain almost 17\% less energy from lunch (11). According to evidence, daily breakfast consumption is associated with choosing healthier foods like fruits and vegetables and will ultimately lead to better nutrition intake (14). Also, several researchers confirmed the relationship between breakfast consumption and higher grades of IQ tests (15), academic achievement, and cognitive functions (16), improved attention at school, and reinforced immediate recall memory in various studies (17). Students who do not have breakfast can be counterproductive to the educational system in reaching its goal. Therefore, it is necessary to identify determinants of optimal nutritional status (18). Theoretical models are useful tools that help in enhancing the knowledge in the field of teenagers' health promotion. Pender's Health Promotion Model, which was introduced in 1982 for the first time and revised in 1986, is an explanatory model regarding healthy behavior which focuses on the role of experience in shaping behavior. The model components are: perceived benefit of action, perceived barriers of action, perceived self-efficacy, prior related behavior, interpersonal influences, situational influences, activity related affect, immediate competing preferences and commitment to a plan of action (19). This model enables health experts to discover a complex bio-psycho-social process which encourages people to adopt health promoting behavior (20). So far, several studies have been conducted in which the health promotion model is used as a predictor of behaviors such as use of hearing protection among workers (21), eating breakfast (7), and oral hygiene (22). Among teenagers, the model performance has mostly been evaluated in terms of physical activity (23, 24); thus, given the importance of nutrition, especially eating breakfast during adolescence, investigating the factors influencing eating breakfast in this age group seems necessary. For this purpose, the current study was carried out to identify factors affecting breakfast consumption among female students of Yazd province, based on Pender's Health Promotion Model.

\section{Material and Methods}

\subsection{Study population and design}

This was a cross-sectional study conducted to examine 200 female high school students of Yazd, selected by cluster sampling method in 2016.

\subsection{Data collection}

A researcher made questionnaire, based on Pender's Health Promotion Model, is used as a tool for collecting required data. For this purpose, it should cover the following items:

1) Demographic items (height, weight, hours of sleep at night, waking hours, etc.)

2) Items associated with Pender's Health Promotion Model; i.e. perceived benefit of action (3 items) e.g. "when I eat breakfast, I understand my lessons better", perceived barriers of action (3 items) e.g. "I don't have time for eating breakfast", commitment to a plan of action (3 items) e.g. "I promise to get up a little earlier in the morning so as to have time for eating breakfast", perceived self-efficacy ( 3 items) e.g. "I myself can prepare my breakfast", situational influences ( 3 items) e.g. "at home, I barely have access to breakfast", activity-related affect (3 items) e.g. "I enjoy eating breakfast", immediate competing preferences ( 3 items) e.g. "I prefer to sleep more rather than eat breakfast" (the achievable score range for each of the above components were 3-15), related behavior (4 items) e.g. "during the past month, I tried to prepare my breakfast myself") The achievable score range was 4-20( and inter-personal influences (5 items) e.g. "during the past month, my family talked about the benefits of eating breakfast" and the achievable score range for this component was 5-25. The items are devised as 5-point Likert scale which range from strongly agree, agree, neutral, disagree, and strongly disagree to always, often, sometimes, rarely, and never. The responses are determined based on the questions.

3) The behavior of having breakfast is measured using this question: "How many times a week do you eat breakfast?" the responses ranged from never to every day with 8 items.

\subsection{Ethics}

This research was approved by the Ethics Committee of Yazd Medical Sciences University with No. p/17/1/128315. The research purpose was explained to the students, who participated with full consent, and the questionnaires were anonymously completed. 


\subsection{Statistical analysis}

In order to approve the validity of this questionnaire, a panel of experts was used. By way of explanation, 8 nutrition and health scholars were given the researcher-made questionnaire to measure CVR and CVI after revision. Based on experts' views, $89 \%$ of CVR and $93 \%$ of CVI were approved. Confirmed reliability of the questionnaire varied between $0.73-0.80$ which is measured by Cronbach's alpha coefficient and internal consistency of data. For data analysis, IBMC SPSS $\odot$ Statistics version 22 (IBM@ Corp., Armonk, NY, USA) was used. Thereafter, for measuring the influence of each component, breakfast consumption path analysis was performed based on Pender's Health Promotion Model using AMOS software (v.23).

\section{Results}

The obtained mean BMI $(\mathrm{kg} / \mathrm{m} 2)$ value of students was $20.68 \pm 3.41$ and the mean frequency of breakfast consumption among them was $4.18 \pm 1.54$ times a week. Twenty three percent of students ate breakfast every day and $3 \%$ of them never ate breakfast. Few students (11.3\%), usually eat a variety of cakes or cookies as breakfast and most of them $(80.7 \%$ ) have breakfast alone. Sleep time and awake time, for most of the subjects, were between 10 to 11 p.m. (36\%) and 6 to $6: 30$ a.m. (45.5\%), respectively. The average scores of the components were: perceived benefits, $11.60( \pm 2.04)$; perceived barriers, $11.60( \pm 2.04)$; self-efficacy, $13.92( \pm 3.34)$; prior related behavior, 11.85 ( \pm 2.94$)$; interpersonal influences, $18.74( \pm 4.78)$; situational influences, $7.51( \pm 2.51)$; activity related affect, 11.60 $( \pm 2.04)$; immediate competing preferences, $8.18( \pm 3.01)$; and commitment to a plan of action, $14.16( \pm 3.22)$. Given that the first presumption was path analysis with maximum likelihood normality of data, normality was tested and approved at first. Then, determinants of breakfast consumption were measured based on Pender's Health Promotion Model, as indicated in Figure 1. Data fitness is also important in path analysis. In Table 1, model fitting indicators, acceptable values, and calculated values for determinants of breakfast consumption are presented. Given that the fitness indicators are not acceptable, modification should be conducted in the model. With the proposed correction indicator of AMOS, variables with the highest coefficient were correlated.

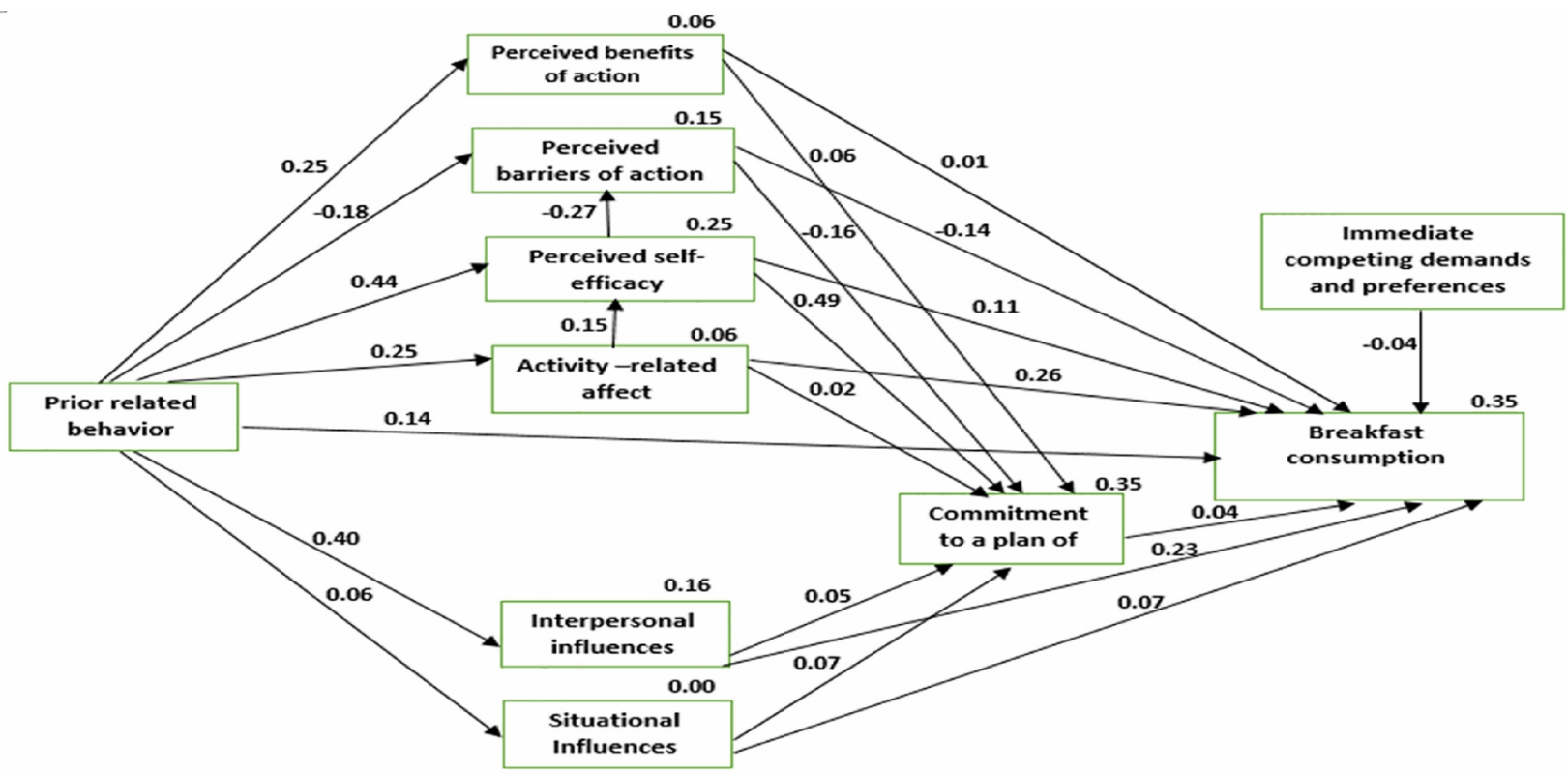

Figure 1. Factors influencing breakfast consumption with standard coefficient

Table 1. Fit indices of breakfast consumption model

\begin{tabular}{|l|l|l|l|l|l|l|l|l|l|l|}
\hline Indices & $\mathrm{X}^{2} / \mathrm{df}$ & RMSEA & NFI & CFI & IFI & RFI & GFI & PRATIO & PNFI & PCFI \\
\hline Acceptable amount & $3<$ & $0.08<$ & $0.9>$ & $0.9>$ & $0.9>$ & $0.9>$ & $0.9>$ & $0.5>$ & $0.5>$ & $0.5>$ \\
\hline Calculated & 7.55 & 0.187 & 0.65 & 0.67 & 0.68 & 0.30 & 0.85 & 0.49 & 0.32 & 0.33 \\
\hline
\end{tabular}

RMSEA = Root Mean Square Error of Approximation, $\mathrm{IFI}=$ incremental fit index, RFI= relative fit index, NFI= Normed Fit Index, PRATIO= parsimony ratio in the output, $\mathrm{PNFI}=$ Parsimonious normed fit index, $\mathrm{PCFI}=$ Parsimonious Comparative fit index, GFI= Goodness of fit, AGFI= Adjusted Goodness of Fit, $\mathrm{CFI}=$ Comparative Fit Index, SRMR= Standardized RMR

In the next phase, with regard to model results, the relationship between prior related behavior and situational influences (significant at 0.430), interpersonal influences and commitment to a plan of action (0.394), situational 
influences and commitment to a plan of action (0.262), situational influences and having breakfast $(0.210)$, immediate competing preferences and having breakfast (0.522), perceived benefits and having breakfast (0.826), self-efficacy and having breakfast (0.178), commitment to a plan of action and having breakfast (0.584), prior related behavior and having breakfast (0.061), perceived benefits and commitment to a plan of action (0.289), activity -related affect and commitment to a plan of action (0.717), were rejected and excluded from the model because of having significance level $\mathrm{p}>0.05$. In addition, during modification, prior related behavior to perceived barriers (0.070) was ignored in the model because of having significance level $p>0.05$. Also, with regard to AMOS corrective indicators and theoretical foundations, three relationships were added by software to improve the fitness of the model. Finally, the modified model was presented as Figure 2. As a result of these modifications, as you can see in Table 2, fitting indices recovered. In Table 3, direct, indirect, and general influences of all variables on having breakfast (path analysis) are given. As you can see, total effect of activity -related affect on breakfast consumption was more than other variables $(0.358)$. The effect of interpersonal influences was direct and significant (0.333). But the effect of perceived barriers to having breakfast was indirect and significant $(0.223)$; i.e. by reducing barriers, breakfast consumption increases. The effects of prior related behavior $(0.249)$ and self-efficacy $(0.057)$ on having breakfast were indirect. Squared multiple correlation coefficients (squared standardized coefficient) showed that research variables justify $33 \%$ of the behavior of having breakfast and the rest in due to that were not considered here.

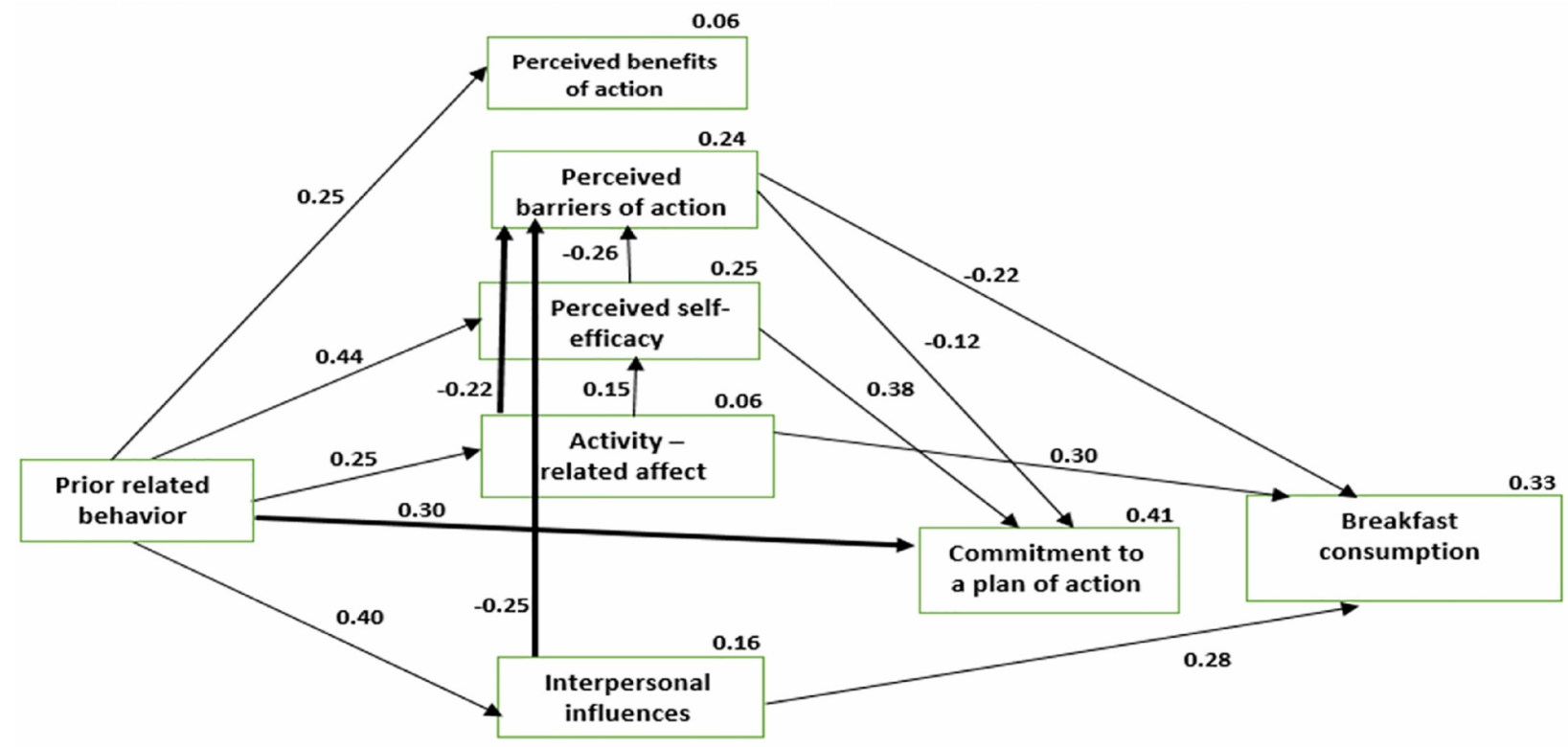

Figure 2. A revised model for factors influencing breakfast consumption with standard coefficient

Table 2. Fit indices of revised model for factors influencing breakfast consumption

\begin{tabular}{|l|l|l|l|l|l|l|l|l|l|l|}
\hline Indices & $\mathrm{X}^{2} / \mathrm{df}$ & RMSEA & NFI & CFI & IFI & RFI & GFI & PRATIO & PNFI & PCFI \\
\hline Acceptable amount & $3<$ & $0.08<$ & $0.9>$ & $0.9>$ & $0.9>$ & $0.9>$ & $0.9>$ & $0.5>$ & $0.5>$ & $0.5>$ \\
\hline Calculated & 1.71 & 0.062 & 0.89 & 0.97 & 0.97 & 0.86 & 0.96 & 0.50 & 0.46 & 0.48 \\
\hline
\end{tabular}

Table 3. Estimation of influences of research variables on breakfast consumption

\begin{tabular}{|l|l|l|l|l|}
\hline Path & Direct influence & Indirect influence & General influence & Test Result \\
\hline $\begin{array}{l}\text { Activity -related affect } \\
\text { Breakfast consumption }\end{array}$ & 0.300 & 0.058 & 0.358 & Accepted \\
\hline $\begin{array}{l}\text { Interpersonal influences } \\
\text { Breakfast consumption }\end{array}$ & 0.276 & 0.056 & 0.333 & Accepted \\
\hline $\begin{array}{l}\text { Perceived barriers of action } \\
\text { Breakfast consumption }\end{array}$ & -0.223 & 0.000 & -0.223 & Accepted \\
\hline $\begin{array}{l}\text { Prior related behavior } \\
\text { Breakfast consumption }\end{array}$ & 0.000 & 0.249 & 0.249 & Accepted \\
\hline $\begin{array}{l}\text { Self-efficacy } \\
\text { Breakfast consumption }\end{array}$ & 0.000 & 0.057 & 0.057 & Accepted \\
\hline
\end{tabular}




\section{Discussion}

Identifying factors that explain the behavior in an intervention training program is very useful and significant. By the same token, this study was designed, implemented and aimed towards identifying determinants of breakfast consumption among students, based on Pender's Health Promotion Model. According to the results obtained from analysis of five components of this model (i.e. positive activity -related affect, interpersonal influences, prior related behavior, perceived barriers of action, and self-efficacy), in total, 33\% of the variance in breakfast consumption among girls is anticipated which is a significant value. The most powerful determinant of behavior in this study was activity -related affect of breakfast consumption that both directly and indirectly affected it by reducing the perceived barriers. Given that, for students, the time for eating breakfast is in line with preparing for and going to school, it is not usually a preferable meal and for that very reason, it is usually disregarded. This finding is similar to the findings of another study in which not wanting breakfast (negative feeling) was regarded as a major cause of not having breakfast among students (25). On the other hand, a positive feeling about eating breakfast induces repetitive behavior as in previous studies; students who regularly ate breakfast stated that after breakfast they had more positive feelings, they were more alert (26), and also, in most cases, were more focused and felt less tired, abdominal pain or backache (27). The next determinant was interpersonal influences that, both directly and indirectly, influenced breakfast consumption by reducing barriers to improving this behavior. This means that when family and friends talk more about the importance of having breakfast with teenagers or accompany them during breakfast, it is more likely that teens regularly have breakfast. This finding is consistent with results of previous studies that suggested factors such as family persuasion and concern regarding eating breakfast, frequency of eating breakfast among family members and groups of friends (all of which are examples of interpersonal influences) have positive effects on breakfast-eating habits of teenagers $(28,29)$. Also it is highlighted that when people have breakfast together with other family members, rather than alone, it is likely to eliminate their breakfast meal (30). Prior related behavior is the third determinant in this study. That is, the more a person has tried to have breakfast, the more probable it is to continue this behavior in future. In fact, repeating a behavior gradually develops it into a habit. It is consistent with findings of previous researches which proved the significance role of prior behavior on its continuity in the future $(7,31)$. The fourth determinant was perceived barriers. It directily had negative influence on the subjects. The more the students feel a barrier related to having breakfast, the less likely they are to have it. Bruening also showed that over-weight concerns and lack of time for eating breakfast are in negative relation with frequency of eating breakfast among adolescents (32). Actually, percieved benefits bring about unpleasant feelings toward breakfast over time and, as mentioned above, adolescents' feelings toward eating breakfast was the strongest predictor of this behavior among them. Thus, by reducing barriers and creating positive feelings in adolescents toward eating breakfast, this behavior can be improved. The last determinant of breakfast consumption was selfefficacy which indirectly, by reducing the perceived barriers, improved this behavior. The more the students feel self-efficacy in relation to preparing breakfast, waking up early morning, etc. the more likely it is in reducing the percieved barriers which finally lead to increased frequency of breakfast consumption per week. In fact, adolescents use their self-efficacy to overcome the barriers. The relationship between self-efficacy and breakfast consumption has been confirmed in other studies (33). Other ways leading to the behavior including perceived benefits, situational influences, immediate competing preferences and commitment to a plan of action were not approved in the analysis. Among the limitations of this study was investigtating only female high school students at grade 2 . Therefore, the results may not be generalized to all adolscents. Also, due to having a large number of components, and to avoid lengthy questionnaires, some components' measurements were confined to the least numer of questions (i.e. 3).

\section{Conclusions}

Given the results, we can say that Pender's Health Promotion Model is a good predictive model for breakfast consumption among students. Given that its components predicted 33\% of breakfast consumption, in planning educational interventions, special attention to these components would be very helpful. Especially in cases where we are dealing with time constraints or resources limitations, with emphasis on these components, the target behavior can be achieved to a considerable degree.

\section{Acknowledgments:}

This research is derived from Ph.D. thesis of Akram Mehrabbeik. Researchers wish to thank the School of Public Health Shahid Sadoughi University of Yazd, Department of Education of Yazd Province, and all teachers and students who helped us with this project. 


\section{Conflict of Interest:}

There is no conflict of interest to be declared.

\section{Authors' contributions:}

All authors contributed to this project and article equally. All authors read and approved the final manuscript.

\section{References:}

1) Moore LL, Singer MR, Qureshi MM, Bradlee ML, Daniels SR. Food group intake and micronutrient adequacy in adolescent girls. Nutrients. 2012; 4(11): 1692-708. doi: 10.3390/nu4111692. PMID: 23201841, PMCID: PMC3509514.

2) Larson N, Fulkerson J, Story M, Neumark-Sztainer D. Shared meals among young adults are associated with better diet quality and predicted by family meal patterns during adolescence. Public health nutr. 2013; 16(5): 883-93 doi: 10.1017/S1368980012003539. PMID: 22857517 , PMCID: PMC3624057.

3) Albertson AM, Thompson DR, Franko DL, Holschuh NM. Weight indicators and nutrient intake in children and adolescents do not vary by sugar content in ready-to-eat cereal: results from National Health and Nutrition Examination Survey 2001-2006. Nutr res. 2011; 31(3): 229-36. doi: 10.1016/j.nutres.2011.03.004. PMID: 21481717.

4) Vereecken C, Dupuy M, Rasmussen M, Kelly C, Nansel TR, Al Sabbah H, et al. Breakfast consumption and its socio-demographic and lifestyle correlates in schoolchildren in 41 countries participating in the HBSC study. Int J Public Health. 2009; 54: 180-90. doi: 10.1007/s00038-009-5409-5. PMID: 19639257, PMCID: PMC3408388.

5) Demissie Z, Eaton DK, Lowry R, Nihiser AJ, Foltz JL. Prevalence and Correlates of Missing Meals Among High School Students-United States, 2010. Am J Health Promot. 2016. doi: 10.1177/0890117116667348. PMID: 27630112.

6) Bagherniya M, Keshavarz SA, Mostafavi F, Sharma M, Maracy MR, Djazayeri SA, et al. Using social cognitive theory in predicting meal frequency in overweight and obese Iranian adolescents. Bull Env Pharmacol Life Sci. 2014; 3(12): 197-203.

7) Dehdari T, Rahimi T, Aryaeian N, Gohari MR, Esfeh JM. Developing and testing a measurement tool for assessing predictors of breakfast consumption based on a health promotion model. J Nutr Educ Behav. 2014; 46(4): 250-8. doi: 10.1016/j.jneb.2013.12.007. PMID: 24637065.

8) Alizadeh SH, Heshmati H, Khademi H, Shamayian Razavi N, Khalafi A. Knowledge and perceived benefits and perceived barriers of students in relationship with their behavior in context of consumption of breakfast and snack in primary schools in Torbat heydariyeh. Journal of Health Chimes. 2013; 1(3): 23-31.

9) Karimi H, Shirinkam F, Sajjadi P, Sharifi M, Bayandari M. Dietary pattern, breakfast and snack consumption among middle school students. J Holist Nurs Midwifery. 2015; 25(2): 73-83.

10) Giovannini M, Agostoni C, Shamir R. Symposium overview: Do we all eat breakfast and is it important? Crit Rev Food Sci Nutr. 2010; 50(2): 97-9. doi: 10.1080/10408390903467373. PMID: 20112150.

11) Astbury NM, Taylor MA, Macdonald IA. Breakfast consumption affects appetite, energy intake, and the metabolic and endocrine responses to foods consumed later in the day in male habitual breakfast eaters. The J Nutr. 2011; 141(7): 1381-9. doi: 10.3945/jn.110.128645. PMID: 21562233.

12) Hallström L, Labayen I, Ruiz JR, Patterson E, Vereecken CA, Breidenassel C, et al. Breakfast consumption and CVD risk factors in European adolescents: the HELENA (Healthy Lifestyle in Europe by Nutrition in Adolescence) Study. Public Health Nutr. 2013; 16(07): 1296-305. doi: 10.1017/S1368980012000973. PMID: 22494882.

13) Antonogeorgos G, Panagiotakos D, Papadimitriou A, Priftis K, Anthracopoulos M, Nicolaidou P. Breakfast consumption and meal frequency interaction with childhood obesity. Pediatr Obes. 2012; 7(1): 65-72. doi: 10.1111/j.2047-6310.2011.00006.x. PMID: 22434740.

14) Sugiyama S, Okuda M, Sasaki S, Kunitsugu I, Hobara T. Breakfast habits among adolescents and their association with daily energy and fish, vegetable, and fruit intake: a community-based cross-sectional study. Environ Health Prev Med. 2012; 17(5): 408-14. doi: 10.1007/s12199-012-0270-1. PMID: 22351508, PMCID: PMC3437357.

15) Liu J, Hwang WT, Dickerman B, Compher C. Regular breakfast consumption is associated with increased IQ in kindergarten children. Early Hum Dev. 2013; 89(4): 257-62. doi: 10.1016/j.earlhumdev.2013.01.006. PMID: 23395328, PMCID: PMC3606659. 
16) Acham H, Kikafunda JK, Malde MK, Oldewage-Theron WH, Egal AA. Breakfast, midday meals and academic achievement in rural primary schools in Uganda: implications for education and school health policy. Food Nutr Res. 2012; 56. doi: 10.3402/fnr.v56i0.11217. PMID: 22347147, PMCID: PMC3280795.

17) Gajre N, Fernandez S, Balakrishna N, Vazir S. Breakfast eating habit and its influence on attentionconcentration, immediate memory and school achievement. Indian Pediatr. 2008; 45(10): 824-8. PMID: 18948652.

18) Busch V, Loyen A, Lodder M, Schrijvers AJ, van Yperen TA, de Leeuw JR. The effects of adolescent health-related behavior on academic performance: a systematic review of the longitudinal evidence. Review of Educational Research. 2014; 84(2): 245-74. doi: 10.3102/0034654313518441.

19) Pender NJ. Heath Promotion Model Manual. Deep Blue. 2011.

20) Ho AY, Berggren I, Dahlborg - Lyckhage E. Diabetes empowerment related to Pender's Health Promotion Model: A meta - synthesis. Nurs Health Sci. 2010; 12(2): 259-67. doi: 10.1111/j.1442-2018.2010.00517.x. PMID: 20602700.

21) McCullagh M, Lusk SL, Ronis DL. Factors influencing use of hearing protection among farmers: A test of the Pender health promotion model. Nurs Res. 2002; 51(1): 33-9. doi: 10.1097/00006199-20020100000006. PMID: 11822567.

22) Vakili M, Rahaei Z, Nadrian H, Yarmohammadi P. Determinants of oral health behaviors among high school students in Shahrekord, Iran based on Health Promotion Model. J Dent Hyg. 2011; 85(1): 39-48. PMID: 21396262.

23) Wu TY, Pender N. A Panel Study of Physical Activity in Taiwanese Youth: Testing the Revised Health Promotion Model. Fam Community Health. 2005; 28(2): 113-24. doi: 10.1097/00003727-20050400000003. PMID: 15778625.

24) Karimi M, Eshrati B. The effect of health promotion model-based training on promoting students' physical activity. J Kermanshah Univ Med Sci. 2012; 16(3): 192-200.

25) Yi BS, Yang IS. An exploratory study for identifying factors related to breakfast in elementary, middle and high school students. Korean Journal of Community Nutrition. 2006; 11(1): 25-38.

26) Widenhorn-Müller K, Hille K, Klenk J, Weiland U. Influence of having breakfast on cognitive performance and mood in 13-to 20-year-old high school students: results of a crossover trial. Pediatrics. 2008; 122(2): 279-84. doi: 10.1542/peds.2007-0944. PMID: 18676544.

27) Olsta J. Bringing Breakfast to Our Students A Program to Increase School Breakfast Participation. J Sch Nurs. 2013; 29(4): 263-70. doi: 10.1177/1059840513476094. PMID: 23420788.

28) Pearson N, Biddle SJ, Gorely T. Family correlates of breakfast consumption among children and adolescents. A systematic review. Appetite. 2009; 52(1): 1-7. doi: 10.1016/j.appet.2008.08.006. PMID: 18789364.

29) Veltsista A, Laitinen J, Sovio U, Roma E, Järvelin MR, Bakoula C. Relationship between eating behavior, breakfast consumption, and obesity among Finnish and Greek adolescents. J Nutr Educ Behav. 2010; 42(6): 417-21. doi: 10.1016/j.jneb.2009.12.004. PMID: 20729150.

30) Sung SJ, Kwon S. Effect of eating with family or alone on the self-rated mental or physical health: the elementary school children in Daejeon area. Korean Journal of Community Nutrition. 2010; 15(2): 206-26.

31) Mullan BA, Wong CL. Hygienic food handling behaviours. An application of the Theory of Planned Behaviour. Appetite. 2009; 52(3): 757-61. doi: 10.1016/j.appet.2009.01.007. PMID: 19501776.

32) Bruening M, Larson N, Neumark-Sztainer D, Story M. Predictors of Adolescent Breakfast Consumption: Longitudinal Findings from Project Eat. Journal of the Academy of Nutrition and Dietetics. 2009; 109(9): A102. doi: 10.1016/j.jada.2009.06.352.

33) Moore GF, Moore L, Murphy S. Normative and cognitive correlates of breakfast skipping in 9-11-year-old schoolchildren in Wales. Appetite. 2009; 53(3): 332-7. doi: 10.1016/j.appet.2009.07.012. PMID: 19631706. 